Revista de la red interuniversitaria de estudios sobre las literaturas rioplatenses contemporáneas en Francia

7 | 2012

Arqueologías

\title{
Julio Cortázar o las barbas del diablo
}

\section{Vera Broichhagen}

URL: http://journals.openedition.org/lirico/595

DOI: 10.4000/lirico.595

ISSN: 2262-8339

Editor

Réseau interuniversitaire d'étude des littératures contemporaines du Río de la Plata

\section{Referencia electrónica}

Vera Broichhagen, « Julio Cortázar o las barbas del diablo », Cuadernos LIRICO [En línea], 7| 2012,

Puesto en línea el 11 octubre 2012, consultado el 01 mayo 2019. URL : http://

journals.openedition.org/lirico/595 ; DOI : 10.4000/lirico.595

Este documento fue generado automáticamente el 1 mayo 2019.

\section{(c) (i) (9)}

Cuadernos LIRICO está distribuido bajo una Licencia Creative Commons Atribución-NoComercialSinDerivar 4.0 Internacional. 


\title{
Julio Cortázar o las barbas del diablo
}

\author{
Vera Broichhagen
}

¿Pero a quién le importa la abuelita de Cortázar?

Aurora Bernárdez

1 Ambigua, contradictoria, bifronte: tal es la figura que se destila de los discursos biográficos del escritor Julio Cortázar. Tenemos por un lado al representante hipermediatizado del boom latinoamericano, que no deja pasar una oportunidad para hacer declaraciones de tipo confesional, y que da entrevistas a la revista Life y a la televisión. Por el otro lado asoma un Cortázar privado, discreto hasta el retraimiento, que nunca terminó de dilucidar algunas zonas de imprecisión de su vida. Los discursos biográficos sobre Cortázar se ajustan de diversas maneras a estas representaciones contradictorias. Algunos eligen tender un velo de discreción sobre las dudas ${ }^{1}$; otros encuentran resoluciones, a veces ficcionalizadas ${ }^{2}$; unas -muy pocas- intentan profundizar y acercarse a los hechos aunque estos sean incómodos. ${ }^{3}$

2 ¿Cuánto hay que saber sobre un autor? Lejos de querer retomar este viejo debate, que no tiene solución única, partiremos de la idea de que la biografía de un autor puede enriquecer la lectura de su obra. Si la biografía presenta lagunas importantes, la tentación es grande de buscar en los textos las piezas faltantes al puzle de la vida del autor.

La crítica anglófona llama crux interpretum a aquellos elementos en un manuscrito antiguo que resultan particularmente herméticos, ya sea por estar sujetos a corrupción material o por otras razones. Una frase puede ser enigmática, y resistirse a toda explicación coherente y ser incomprensible en su contexto. Si se imagina la obra como una carta, estos elementos constituyen tantas encrucijadas (hasta la grafía del término - la equis de crux- evoca una intersección) en las que generaciones de exégetas coinciden para ponderar el enigma, a veces durante años. Hay ejemplos famosos. ${ }^{4}$ Podríamos valernos del término, adaptándolo, para crear la noción de crux biográfica: se trataría de las zonas enigmáticas en el relato conocido de la vida de un autor; de las incoherencias, inconsistencias o (aparentes) deslices, inexplicables a la luz del recorrido previo. Zonas de encuentro -y, como veremos, de desencuentro- para los biógrafos. ${ }^{5}$ Así, las zonas oscuras en los discursos biográficos de Cortázar merecen atención por el simple hecho de que 
tocan cuestiones tan transcendentes como el origen, la identidad, la primera lengua, la muerte.

4 Los más insistentes de estos enigmas -desprestigiados por tan conocidos- pueden resumirse rápidamente : ¿Por qué nació Cortázar en Bélgica -accidentalmente y por un "capricho del destino", como rezan muchas solapas y contratapas de sus libros? ¿Cuál fue la verdadera actividad de su padre en Bélgica? ¿Cuál fue la primera lengua que habló Cortázar niño ? Su acento, ¿se debe al aprendizaje del francés como primera lengua, o a un defecto vocal ? ¿Cómo entender su abandono de la Argentina : como exilio, huida, o acaso como un retorno? ¿Cuál es el motivo de su inexplicable sometimiento a la línea revolucionaria cubana, aún en un tiempo en que para muchos ésta ya no se dejaba sostener? ¿Cómo interpretar los mea culpa que multiplica a partir de 1963 ? ¿Por qué, maestro del cuento fantástico, se lanza, ya grande, a escribir ficción "política" ? ¿De joven, fue tan poco politizado como lo dijo ?

5 Publicado en 2004, el libro de Montes-Bradley (Cortázar sin barba) intenta pulverizar algunas de las más robustas leyendas cortazarianas. El autor se rebela contra la falta de rigor en la investigación -acusación que incluye al propio Cortázar, en quien MontesBradley ve al primer responsable por la acumulación de mitos alrededor de su persona. El propósito del biógrafo es "desmembrar" la figura de Cortázar, refutar los otros textos biográficos $\mathrm{y}$, de paso, enjuiciar la falta de disciplina en las investigaciones cortazarianas $y$, por extensión, en el trabajo biográfico en general. La insolente "anti-biografía" de Montes-Bradley empieza por examinar los orígenes del escritor, en particular su nacimiento en Bélgica, una circunstancia calificada de "accidental" en las solapas y contratapas de no pocos libros sobre Cortázar. El libro de Montes-Bradley refuta esta noción de "capricho del destino", demostrando que los padres de Cortázar estaban en Europa porque soñaban con establecerse allí de manera permanente. Montes-Bradley ve en el adjetivo "accidental" - tan cortazariano, por cierto- un intento patético de "argentinizar" al escritor. Esfuerzo fútil, ya que Cortázar no necesita ninguna argentinización; su nacimiento belga y su muerte francesa no lograron quitarle la idiosincrasia y el habla de este país. Si se impone la idea que Cortázar hablaba con un acento francés es, según Montes-Bradley, porque "un Cortázar con acento francés es infinitamente más simpático y atractivo, más a la medida de lo que quisiéramos que fuera." ${ }^{16} \mathrm{El}$ tono irónico y hasta jocoso con el que se presentan las averiguaciones acompaña una gran minucia en las investigaciones. He aquí una muestra del texto :

La idea de un nacimiento azaroso es lo suficientemente descabellada como para convertirse en pretexto de uno de los relatos del autor al que bien podríamos titular: No quiso pero nació igual, o ¿Qué hace un bebé como yo en un lugar como éste? Después de todo, Cortázar nació a los nueve meses como estaba previsto y en el mismo lugar en el que se encontraba su madre, lo cual facilita la labor de las parteras en cualquier sitio del mundo y también en Bélgica, donde ocurrió el contratiempo. [...] En un intento por argentinizarlo, señalan que el escritor adopta la nacionalidad argentina de sus padres, lo cual es lisa y llanamente otra de las mentiras con las que se busca fundir en bronce al autor. [...] El pasaporte que Francia le otorga no es el resultado del capricho de sus padres; es la conclusión de un arduo y penoso proceso que requiere, ante todo, de su voluntad y esfuerzo. ${ }^{7}$ estudioso acude con preguntas detalladas y expone su proyecto biográfico, le lanza un día : "¿Pero a quién le importa la abuelita de Cortázar ?". Este comentario le da pie al joven investigador para justificarse : 
Son pocas las familias [...] que conservan los talismanes de la memoria tribal, que servirán a los expertos, después, para reconstruir y estudiar la verdad del pasado. [...] De estos mensajes recibidos -y a su vez enviados- nace la continuidad de la cultura, lo específicamente eterno que identifica al ser humano como tal. Porque, ¿qué otra cosa es, al fin y al cabo, La Ilíada, sino el contenido de un morral repleto con los desechos de la memoria de un bardo itinerante ? ${ }^{8}$

Montes-Bradley cita un pasaje de las Conjeturas sobre la memoria de mi tribu del chileno José Donoso, que expresa bien lo que él mismo intenta hacer : defender el género biografía concebido como arma para combatir el retraso cultural latinoamericano. Especie de biografía-guerrilla, actúa como como repositorio de la Memoria y por lo tanto facilitadora de Civilización. Un tal programa exige una ética del detalle, de los números, del nombre deletreado correctamente, de la cita usurpada devuelta a su verdadero autor. El libro del cineasta adhiere estrechamente a esta deontología y desmantela los mitos del acento francés, del padre diplomático, de una enfermedad llamada gigantismo, del joven Cortázar conservador-nacionalista-falangista. Irónicamente, el crítico averigua algo que le hubiera encantado a Cortázar si lo hubiera sabido: el escritor era primo en noveno grado de su "hermano en la sierra", su admirado Ernesto Che Guevara.

Estos mitos no dejan por eso de integrar esta memoria colectiva, problemática, reveladora de tensiones históricas, lapsus y arreglos de cuentas. No es descabellado afirmar que la lectura lúcida de las malas biografías -las apócrifas, las complacientes, las inexactas, las biografías-arregladoras-de-cuentas- sea tan instructiva como la de las escrupulosas. Pensemos en el personaje borgeano Ryan Kilpatrick, bisnieto y biógrafo del héroe Fergus en "Tema del traidor y del héroe". La garrafal mise-en-scène de Nolan que instaura a Fergus Kilpatrick como héroe indiscutible de la Revolución irlandesa, y a la vez lo sacrifica, lleva al extremo la idea de la instrumentalización de un individuo con fines nacionalistas. Con algo de descaro, se podría leer allí una versión de la historia del traidor Cortázar -no el belga-argentino, esta vez, sino el cubano y socialista que firmó la primera carta de protesta al gobierno revolucionario durante el famoso caso Padilla. Luego de un ambiguo mea culpa (cartas en prosa y verso a mitad de camino entre la auto-inculpación y la autojustificación) ${ }^{9}$ que está en las antípodas del Mea Cuba de Cabrera Infante (una recopilación de textos en parte muy críticos sobre temas cubanos), Cortázar fue llevado al escenario por su propia versión de Nolan, Fidel Castro. Si existen versiones falsas, contradictorias, inventadas de la vida de un personaje ilustre, es interesante ver el porqué de estas versiones. No lleva a preguntar por qué se construye una cierta figura en una determinada coyuntura socio-política; y qué motiva al biografiado a hacerse cómplice de la confabulación. Hay que mirar el contexto.

Para el caso que nos interesa, son reveladoras las controversias en las que se vio implicado Cortázar (las polémicas mediatizadas con Oscar Collazos, José María Arguedas, Josefina Ludmer ; o las discusiones sobre El libro de Manuel en La Opinión Cultural en 1974 en la que participan Ricardo Piglia, Haroldo Conti, Ernesto Goldar, Jorge Abelardo Ramos y María Rosa Oliver). Claudia Gilman analiza estos "Debates y dilemas del escritor revolucionario en América Latina" (es el subtítulo de su libro) en Entre la pluma y el fusil. ${ }^{10}$ Las polémicas mencionadas, que trataban en su mayoría la cuestión de las responsabilidades y libertades del escritor latinoamericano, sólo se pueden aprehender cabalmente a la luz del contexto intelectual de los años sesenta y setenta. Cortázar se exponía a la crítica, primero por su emigración a París en 1951, pero también por el elitismo pequeño-burgués del que se auto-acusó en tanto revolucionario convertido y arrepentido ; por su ambición de crear literatura comprometida sin renunciar del todo a 
su estética inspirada de los surrealistas (El libro de Manuel) ; por querer ser revolucionario latinoamericano y parisino a la vez. Con todo aquello, se prestaba admirablemente para ser declarado "otro" por cofradías de intelectuales que lo usaron para desquitarse, tal vez, de un resto de complejo de inferioridad cultural, o bien para confirmarse solidariamente su identidad. ${ }^{11}$

\section{Las barbas del diablo}

De manera análoga a lo que sucede con el filósofo alemán Ludwig Wittgenstein (1889-1951), las numerosas biografías de Julio Cortázar insisten en la idea de una escisión interna, que determinaría dos periodos dentro de su obra: se habla, entonces, del "primer" y del "segundo" Cortázar, o bien de los "dos Julios", que de acuerdo a esta visión se enfrentarían como dos polos opuestos. Es llamativa la tendencia de muchos biógrafos a ensalzar un período a costa del otro: unos alaban al Cortázar joven por su prosa libre, imaginativa, desprovista de ideologización; otros encomian al Cortázar maduro por su acérrima devoción a la causa justa. En este juego de Jeckyll contra Hyde, la barba funciona como el signo -o síntoma- de una transformación que marca un nuevo comienzo. ${ }^{12}$ ¿Qué significa? Que el adolescente cincuentón ha llegado por fin a la adultez, que ha alcanzado una integridad cidiana; o ha conquistado la libertad sexual tan pilosa de los años sesenta y setenta? Sea como fuere, merece atención esta cesura que atraviesa casi todas las biografías del autor -y que determina el comienzo o final de algunas de ellas. La pregunta implícita sobre cuál de los dos Julios es el "verdadero" implica, falsamente, que uno de ellos es irreal, o soñado por el otro, tal vez, como en "Las ruinas circulares" de Borges. Están también aquellos para los que no es rescatable ni el imberbe ni el barbado. El cubano Cabrera Infante escribe que Cortázar fue "uno que para disfrazarse del Che en París acudió a hormonas y barbas postizas y poder adoptar así el lenguaje 'marzista' à la mode. París bien vale una máscara." ${ }^{13}$ Cortázar no hizo mucho para mitigar estas críticas. Aún de sus justificaciones emerge un individuo maleable, incierto, que se presta para ser construido y reconstruido, actitud que no pocas veces lo dejó en el centro de disputas y polémicas para él dolorosas.

11 Quisiera demostrar al ejemplo de una entrevista el discurso escindido -casi esquizofrénico- de Cortázar, que contribuyó no poco a alimentar el coro de reproches que lo acompañó durante casi toda su carrera literaria. Se trata de la famosa entrevista que concedió a Life en abril 1969. ${ }^{14}$ Dentro de los treinta años de declaraciones que tenemos del Julio Cortázar pos-Rayuela, el género de la entrevista literaria toma un lugar privilegiado, junto con las cartas cuando éstas fueron publicadas. ${ }^{15}$ La entrevista literaria es una de las principales fuentes de información para biógrafos, ya que al dar una entrevista, el escritor procesa y edita la materia prima. En cuanto ejercicio discursivo, "performativo" y altamente codificado, la entrevista literaria es un espacio de reconfiguración constante de la imagen del autor. Más que una producción ex nihilo, sirve para regular la imagen pública vigente a través de una negociación estratégica, de la cual participa también la ficción. Especie de máquina productora de una figura de autor en constante mutación, la entrevista participa de un género híbrido : es en parte producción crítica secundaria y en parte obra del autor. El americano John Rodden examinó la dinámica compleja de la entrevista literaria, llegando a la conclusión de que el entrevistador (quien trae las preguntas, hace de facilitador, y establece la dirección general del diálogo) suele estar en una posición de inferioridad con respecto al autor en 
tanto celebridad. Rodden califica esta relación jerárquica de power imbalance desequilibrio en las relaciones de poder entre un "escritor conocido" y un "estudioso anónimo"-. ${ }^{16}$

12 En ocasiones, Cortázar supo explotar este desequilibrio, como por ejemplo en la entrevista publicada en la revista LIFE, para la que impuso la condición inédita de control total sobre el texto publicado (algo que no se había concedido a nadie hasta la fecha). ${ }^{17} \mathrm{El}$ resultado de este control, sin embargo, es problemático. De manera llamativa, la entrevista se vuelve recitación: la voz de la entrevistadora Rita Guibert no aparece directamente ni una sola vez. Aparece un Cortázar que se ha dejado contaminar por la cultura del monólogo que se está instalando en Cuba en ese momento de 1969 (un monólogo en que, paradójicamente, denuncia los "falsos diálogos" que ofrece una revista como Life) ; un Cortázar que -por lo menos momentáneamente- se ha dejado amordazar. El tono algo dogmático del escritor contrasta con la generosa nota editorial, levemente divertida ante el entusiasmo militante del escritor :

[...] aunque, como dice en su entrevista, considera a LIFE un adversario maquiavélico, nosotros vemos en él a un gran escritor en lengua española, con cuyos puntos de vista políticos no comulgamos. $Y$ aunque en el fondo él y nosotros busquemos la plenitud humana, discrepamos en cuanto a los medios de alcanzarla. Lo cual no obsta para que respetemos y publiquemos sus opiniones. ${ }^{18}$

13 Al mismo tiempo que explota su notoriedad con fines de proselitismo socialista, el escritor célebre trabaja como títere de unos comisarios culturales cubanos, muy amigos por cierto, poniendo a disposición su notoriedad para uso revolucionario. Y va más lejos aún : en una carta a Francisco Retamar, director de la Revista Casa de las Américas, Cortázar justifica haber aceptado hacer la entrevista, corrigiendo anticipadamente los mínimos descarríos que pudo haber cometido en la entrevista al aclarar su versión personal de humanismo socialista :

[...] En este tiempo de malentendidos frecuentes, me interesa que estés enterado de esto, que lo estén Haydée y todos los amigos de la Casa. Cuando salga la entrevista, te enviaré inmediatamente un número ; entonces, podrás juzgar [...]. ${ }^{19}$

14 En la entrevista, como en otras ocasiones, el escritor comprometido mantiene un diálogo con los reaccionarios, entre los que parece incluir al Cortázar de antes, en un tono ligeramente defensivo :

[...] mi idea del socialismo no se diluye en un tibio humanismo teñido de tolerancia ; si los hombres valen para mí más que los sistemas, entiendo que el sistema socialista es el único que puede llegar alguna vez a proyectar al hombre hacia su auténtico destino; parafraseando el famoso verso de Mallarmé sobre Poe (me regocija el horror de los literatos puros que lean esto) creo que el socialismo, y no la vaga eternidad anunciada por el poeta y las iglesias, transformará al hombre en el hombre mismo. [El subrayado es mío]

15 Al caer en referencias cultas y mallarmeanas, el diálogo con los "literatos puros", con toda la connotación de militancia que implica esa terminología, es más revelador del "literato puro" que sigue siendo Julio Cortázar. ${ }^{20}$ En su esfuerzo por demostrar coherencia, Cortázar en realidad manifiesta una incapacidad de superar o de abandonar ciertas preferencias y sensibilidades juzgadas incompatibles por su nuevo estatus de escritor revolucionario. Para colmo, no deja de decirlo él mismo. Basta avanzar un poco en la misma entrevista de Life para encontrarnos con frases : "...un escritor vocacional se debe a sí mismo el ser eso [un escritor profesional] en vez de trabajar a ratos perdidos, como yo y otros que escribimos por una especie de lujo bastante burgués en el fondo." ${ }^{21}$ 


\section{"El perseguidor" : un ejemplo de discurso meta- biográfico}

16 La pregunta por los motivos de tales contradicciones, que se aproximan a un sistemático "borrado de pistas", viene acompañada por la cuestión de la relación entre textos de no ficción y producción literaria. Admitiendo que los datos biográficos son significativos sólo si echan luz sobre la obra, contamos con que la biografía nos proporcionará elementos para explicar la escritura. Pero ¿es legítimo auscultar la obra para detectar causas o efectos de eventos biográficos? Y ¿no significa esto meterse en un endiablado círculo tautológico? Si tenemos en cuenta las declaraciones del propio Cortázar, la cuestión es sin duda relevante, puesto que afirma que la "experiencia" de escritura de "El perseguidor" lo preparó para la aventura cubana y socialista.

17 En Respiración artificial, Ricardo Piglia pone en boca de su alter ego Emilio Renzi la hipótesis de que el verdadero Borges está en su ficción, no en las declaraciones con las que construyó la figura de autor. Del mismo modo, la ficción de Cortázar encierra reflexiones que -se puede suponer- prefirió no expresar directamente. Así, por ejemplo, sus reflexiones sobre el género de la biografía y la actitud de los biógrafos. Su nouvelle "El perseguidor" tematiza tanto estas cuestiones como la relación entre artista y biógrafo. En el retrato negativo del biógrafo Bruno -un ser pusilánime e interesado, el "Salieri" (conoce sus limitaciones) del genio Johnny- se puede leer un comentario de Cortázar no sólo sobre el género biografía, sino sobre su propia relación con aquéllos que se ocupan de su vida. Con el relato, reubica el marco dentro del cual se dan los debates alrededor de su propia biografía.

18 Conviene mirar más detenidamente este relato largo. El narrador es Bruno, crítico de música, gran admirador y, además, como ya apuntamos, biógrafo del jazzman Johnny. Bruno nos cuenta "en directo" el declive de los últimos años de la vida de Johnny, al que asiste como espectador empático. Sigue las peripecias del músico adicto, enfermo, arruinado en todos los sentidos de la palabra. Como el doctor Hardoy ante sus "monstruos" en "Las puertas del cielo", la fascinación que siente Bruno por Johnny está mezclada de temor. Al mismo tiempo, ambos narradores-protagonistas se sirven del "otro" para afirmar su propia identidad:

De manera que al final me he ido de la pieza [...] ; me ha parecido que París olía a limpio, a pan caliente. [...] He entrado en un café para beber un coñac y lavarme la boca, quizá también la memoria que insiste e insiste en las palabras de Johnny, sus cuentos, su manera de ver lo que yo no veo y en el fondo no quiero ver. ${ }^{22}$

19 A través de la autocrítica de Bruno, eco también de sus carencias y mezquindades, el texto denuncia la instrumentalización del artista por parte de una industria editorial. Esta última constituye una verdadera conspiración de la que es cómplice el biógrafo, quien se sirve aún de la muerte del músico :

Todo esto coincidió con la aparición de la segunda edición de mi libro, pero por suerte tuve tiempo de incorporar una nota necrológica redactada a toda máquina, y una fotografía del entierro donde se veía a muchos jazzmen famosos. En esa forma la biografía quedó, por decirlo así, completa. Quizá no esté bien que yo diga esto, pero como es natural me sitúo en un plano meramente estético. Ya hablan de una nueva traducción, creo que al sueco o al noruego. Mi mujer está encantada con la noticia. (p. 223) 
palabras de Bruno traducen la hipocresía del "estudioso anónimo" que avanza motivos estéticos donde hay sobre todo cálculo materialista de un pequeño-burgués que busca complacer a su señora. Como Hardoy, Bruno participa -desde una distancia segurade la vida del genio, cuya superioridad creativa compensa con una irreprochabilidad burguesa. Pero esto no le impide esto reconocer su propia cobardía y realizar una autocrítica colectiva :

En el fondo somos una banda de egoístas, so pretexto de cuidar a Johnny lo que hacemos es salvar nuestra idea de él, prepararnos a los nuevos placeres que va a darnos Johnny, sacarle brillo a la estatua que hemos erigido entre todos y defenderla cueste lo que cueste. (p. 189) Bruno confiesa la canibalización del artista por el biógrafo y reconoce la naturaleza interesada de su propia relación en él : "El fracaso de Johnny sería malo para mi libro [...], y probablemente de cosas así está hecha una parte de mi cuidado por Johnny." (p. 189)

Cortázar escribió el relato en 1959, es decir, antes del primer viaje a Cuba y antes de la publicación de Rayuela. Con este texto, nos da una autobiografía desplazada tanto en el género -una ficción que encierra una biografía- como en el tiempo: parece hablar prolépticamente- del Cortázar post-1963. Especie de prefiguración de su propia historia, Cortázar se resiste a volverse carne del "cañón" literario que lo espera.

Para el crítico literario, existe una indudable tensión entre la necesidad de poner en duda constantemente los beginnings de un autor; y la exigencia de detener este cuestionamiento para poder proceder a un análisis de su obra. Los discursos biográficos de Cortázar ilustran bien este dilema. Respondiendo a la pregunta (por cierto retórica) de Aurora Bernárdez, diríamos que no importa tanto la abuelita de Cortázar, como la manera en que Cortázar habla de ella, o, ya que estamos, de su madre, de su hermana Ofelia; la manera en que no habla (o muy poco) de su padre; y porqué lo hace. Vanguardista, divulgador de una máxima apertura en lo estético, Cortázar usó los procedimientos poéticos de la "obra abierta" para que su biografía fuese, en todo momento, coherente, completa, definitivamente cerrada.

\section{NOTAS}

1. Ver, por ejemplo, K. Berriot, Julio Cortázar l'enchanteur, París : Presses de la Renaissance, 1988.

2. E. Fernández Cicco, El secreto de Cortázar, Buenos Aires : Editorial de Belgrano, 1999.

3. E. Montes-Bradley, Cortázar sin barba, Buenos Aires : Sudamericana, 2004.

4. Las piezas de Shakespeare presentan casos conocidos de estos pasajes ininteligibles. Un ejemplo conocido de una crux es la frase con la que una anfitriona describe a Falstaff en Henry $V$ : "Su nariz era afilada, como un cuchillo y una mesa de pastos verdes". Así dice la versión del primer Folio, En el original : "...his nose was sharp as a pen, and "a Table of green fields." La corrección de Lewis Theobald, "and 'a [he] babbl'd of green fields," ha sido retomada por casi todos los editores subsiguientes.

5. Cabe recordar aquí las dos definiciones de crux en inglés : por un lado : "punto o rasgo básico, central o crítico de algo" (The basic, central, or critical point or feature : the crux of the matter) ; por el

Cuadernos LIRICO, 7 | 2012 
otro: "problema desconcertante y aparentemente insoluble" (A puzzling or apparently insoluble problem).

6. Montes Bradley, op. cit., p. 120.

7. Ibid., p. 22.

8. J. Donoso, Conjeturas sobre la memoria de mi tribu, citado por Montes-Bradley, op. cit., p. 23.

9. Estoy pensando, por ejemplo, en el texto "Policrítica a la hora de los chacales" (1971), incluido en una carta a Haydée Santamaría y publicado en la revista de la Casa de las Américas en 1972.

10. C. Gilman, Entre la pluma y el fusil. Debates y dilemas del escritor revolucionario en América Latina., Buenos Aires : Siglo XXI, 2003.

11. Ver en este contexto el ensayo de D. Viñas De Sarmiento a Cortázar, Literatura argentina y realidad política, Buenos Aires : Siglo XX, 1970. Viñas le dedica un capítulo a Cortázar ("Cortázar y la fundación mitológica de París").

12. Cortázar empieza a llevar barba por el año 1967. Es símbolo tanto de la identificación del autor con los barbudos cubanos como de su acercamiento a la pilosa liberación sexual de los años sesenta y de la vida posterior a su matrimonio con Aurora Bernárdez (se separan en 1968). La barba en sí es un enigma hasta para la hermana del eterno lampiño.

13. Escrito en ocasión de la muerte del crítico uruguayo Emir Rodríguez Monegal, para quien, según Cabrera Infante, Cortázar fue el "más encarnizado perro de presa". Citado en MontesBradley, op. cit., p. 15.

14. Life en español, vol. 33, No. 7, 7 de abril de 1969.

15. J. Cortázar, Cartas (en tres volúmenes), edición a cargo de Aurora Bernárdez, Buenos Aires : Alfaguara, [Biblioteca Cortázar], 2000.

16. J. Rodden, Performing the literary Interview: How Writers Craft their Public Selves, Lincoln, University of Nebraka Press, 2001.

17. También en su correspondencia, las alusiones a la biografía son frecuentes. Muchas de ellas toman la forma de palabras irónicas dirigidas por el joven Cortázar a sus futuros biógrafos -un gesto en el que es difícil a veces distinguir entre falsa modestia y verdadera coquetería. Desde joven, el futuro escritor mantiene un diálogo con sus futuros biógrafos. En una carta a Mercedes Arias de marzo 1942, dice : "No se extrañe de mi insistencia ; tengo que poner en orden los datos para mi biografía, y no quiero malos entendidos." Cartas, op. cit., vol. 1.

18. Life, op. cit. Nota de la dirección, por Alberto R. Cellario, Director General, p. 1

19. Cartas, op. cit., vol. 3, p. 1324.

20. Por otro lado, de un total de once páginas que ocupa la entrevista, las dos páginas y media iniciales, que tratan exclusivamente del compromiso del escritor con Cuba, funcionan también como pretexto : representan el deber cumplido que autoriza a que el escritor se explayara sobre literatura en las nueve páginas restantes.

21. Life, op.cit., p. 50.

22. J. Cortázar, "El perseguidor", en Relatos 3. Pasajes, Madrid : Alianza, 1976, p. 183. Los números de página entre paréntesis remiten a esta edición.

\section{RESÚMENES}

El artículo propone retomar los discursos biográficos de Julio Cortázar, habiendo constatado la presencia de zonas secretas en su vida privada, lo que contrasta con la ultra exposición mediática 
del autor. Efectivamente, el análisis de algunos episodios de su historia íntima, en particular los de la infancia y los de sus comienzos en tanto que escritor (sus beginnings), permiten arrojar una luz nueva sobre la construcción de la imagen de una figura de autor muy poderosa y muy determinante en la recepción de los textos.

L'article propose de revenir sur les discours biographiques de Julio Cortázar, se concentrant sur la présence de zones d'ombre dans sa vie privée, ce qui s'oppose à l'ultra-exposition médiatique de l'auteur. En effet, l'analyse de quelques épisodes de son histoire intime, en particulier ceux de l'enfance et de ses débuts en tant qu'écrivain (ses beginnings), permettent d'éclairer d'un jour nouveau la construction de l'image d'une figure d'auteur très puissante et déterminante dans la réception des textes.

The article proposes revisiting Julio Cortázar's biographical discussions, concentrating on the presence of shadowy areas or secret aspects of his private life, which are in contradiction to the author's extreme media exposure. For example, the analysis of a number of episodes from his personal life, in particular those of his childhood and his beginnings as a writer, sheds new light on the construction of the image of a very powerful author figure, a determining factor in the reception of his texts.

\section{ÍNDICE}

Mots-clés: Cortázar, biographie, beginnings, image, figure d'auteur

Keywords: biography, author figure

Palabras claves: imagen, figura de autor

\section{AUTOR}

\section{VERA BROICHHAGEN}

Université Paris 8 Vincennes - Saint-Denis/Princeton University 